\title{
Intellectual Performance in Multi-Infarct Dementia and Alzheimer's Disease A Replication Study
}

\author{
FRANCISCO I. PEREZ, DAVID A. STUMP, JOE R. A. GAY, AND VICKI R. HART
}

SUMMARY: A consistent feature in dementia is an overall intellectual deterioration. The present study investigated the intellectual performance of patients with Alzeheimer's disease (AD) and multi-infarct dementia (MID) using the Wechsler Adult Intelligence Scale (WAIS). For reliability and generality purposes two independent samples of patients were collected. Significant differences in Education Level (EDU) and Performance IQ (PIQ) were obtained for the first sample, with the $A D$ group having a significantly higher EDU level. The MID group obtained a higher PIQ. No significant differences were found in the second sample, but EDU level approached significance with the $A D$ group again having a higher EDU level. A discriminant function analysis classified $81 \%$ of the patients in the first sample

RESUMÉ: La détérioration mentale est fréquente dans la démence. La présente étude étudie la performance intellectuelle chez des patients atteints de la maladie d'Alzheimer $(A D)$ et de démence pluri-lacunaire (MID) en utilisant l'échelle d'intelligence de Wechsler (WAIS). Deux groupes indépendants de patients furent rassemblés. Des différences significatives dans le niveau d'éducation (EDU) et la performance dans le Q.I. (PQI) furent obtenues pour le premier échantillon, le groupe $A D$ ayant un niveau EDU significativement plus élevé. Le groupe MID obtenait une plus haute PQI. II n'y avait pas de différences significatives dans le second échantillon, mais le niveau EDU était presque significatif, le groupe $A D$ ayant encore un niveau EDU plus élevé. Une analyse de fonction discriminatoire classifiait and $100 \%$ diagnostic accuracy was obtained for the second sample using the 11 predictor variables. $A$ maximum $R^{2}$ stepwise regression was performed in order to detect the "best" model of variables discriminating between the diagnostic groups. For the first sample the "best" model was the two variable model, including EDU and Full Scale $I Q$, accounting for $40 \%$ of the variance. The simplest model for the second sample was the one variable model including $E D U$, accounting for $20 \%$ of the variance. Quantitative differences were found between the $A D$ samples. Time since onset of the disease was offered as a possible influence in the quantitative differences in the AD samples. Sampling biases in the behavioral study of dementia are discussed. Successful replication was oblained.
$81 \%$ des patients dans le premier échantillon et $100 \%$ d'exactitude de diagnostic fut obtenue pour le second échantillon en utilisant les 11 variables de prédiction. Une analyse de régression fut effectuée dans le but de détecter le 'meilleur' modèle de variables discriminatoires entre les groupes diagnostic. Pour le premier échantillon, le "meilleur" modèle était le modèle à 2 variables incluant EDU et l'échelle complète de QI comptant pour $40 \%$ de la variance. Le modèle le plus simple pour le second échantillon était le modèle à une variable incluant EDU et comptant pour $20 \%$ de la variance. Des différences quantitatives furent trouvées entre les deux échantillons $A D$. Le temps depuis le début de la maladie est peut-être une influence possible dans les différences quantitatives entre les échantillons $A D$.

\section{INTRODUCTION}

Dementia is a disruption of behavior with impairment in the ability to learn new responses and thus to adapt to a changing environment (Perez et al, 1975a). Psychological and intellectual changes are the essential elements for a diagnosis of dementia. Pearce and Miller (1973) as well as Perez et al, (1975 a, b, c) have demonstrated the usefulness of a detailed psychological evaluation in describing the patterns of neuropsychological deficits in the various dementias. Perez et al (1975 b) identified four distinct aspects of the neuropsychological approach to dementia including: 1) the measurement of intellectual memory, language and perceptual - motor functioning of the patient, 2) the development of refined and precise psychological and behavioral measures to differentiate and classify patients into the various diseases producing dementia, 3) the detailed description of the nature and course of the psychological disturbances associated with specified disease entities, and 4) the assessment of medical and environmental therapeutic interventions.

Recent studies have shown that old age and dementia are far

From the Departments of Neurology and Psychiatry, Baylor College of Medicine, and the Baylor-Methodist Center for Cerebrovascular Research, Houston, Texas U.S.A.

This work was supported by Grant NSO 9287 from the National Institute of Neurological Diseases and Stroke, and in part from NIH Grant RR-00259 for computational activities.

Reprint requests to: Francisco I. Perez, Ph D., Department of Neurolody, Baylor College of Medicine, 1200 Moursund Avenue, Houston, Texas 77030. U.S.A. 
from synonymous (Poser, 1975; Hachinski et al, 1974; Heilman and Wilder, 1971). Kral (1972) indicates that dementia is not the final outcome of normal cerebral aging but seems to be a disease process which is different from normal aging. Studies have also shown that whereas some dementias are currently untreatable, many are treatable. Dementia and other neurologic signs and symptoms arising from metabolic disturbances are often characterized by complete reversal of symptoms and return to normal function if properly treated. At present, no therapy is offered for multiinfarct dementia (MID) and dementias due to neuronal atrophy of the Alzheimer type (AD) which are the most common disorders associated with a dementing process. Meyer et al (1975) in reviewing the evidence concerning these common types of dementia suggest a disordered neurotransmitter synthesis, release and reuptake process which may be due to 1) decreased perfusion and oxygen supply with resulting failure of energy for neurotransmitter synthesis as seen in MID, or 2) primary failure of cerebral enzyme synthesis as seen in AD. Differential diagnosis of the various dementias is important since treatment and prognosis differ.

Most investigators agree that a consistent feature in dementia is an overall intellectual deterioration. However, dementia as a syndrome of behavioral and cognitive reduction may be produced by a wide variety of etiologies, and the specific clinical and intellectual deficits may vary according to the cause, the localization of the etiologic process within the central nervous system, the rate of progression, the age of onset and various environmental factors (Karp, 1974). Perez et al (1975a) found significant differences in cognitive and intellectual performance on the Wechsler Adult Intelligence Scale (WAIS) between patients with dementia secondary to vertebrobasilar insufficiency (VBI) or MID versus $A D$. A discriminant function analysis classified $74 \%$ of the patients correctly based on the individual WAIS scores. The clas- sification of patients was more easily obtained when tasks measuring visual motor coordination and abstract reasoning were included in the analysis. It was easier to classify patients who were either maximally impaired (AD) or minimally impaired (VBI) from a cognitive viewpoint. The data suggested that the MID group was less homogeneous in their cognitive performance as might be predicted from the patchy nature of the disease process. It is the purpose of the present study to investigate the intellectual performance of patients with MID and AD using the various subtests of the WAIS. Two independent samples of patients were used in an attempt to obtain a measure of reliability for replication purposes. The results are discussed within the context of previous findings (Perez et al, 1975a).

\section{METHOD}

Patient Selection - All 57 patients participating in the study were followed up at least a year or more with numerous re-examinations. A neurologist classified the patients into the two diagnostic groups on the basis of a complete clinical and laboratory evaluation. This required careful inspection of the records of over 160 demented patients, and the 57 patients were admitted to the study after the diagnosis was objectively confirmed. In three AD cases and two MID cases the diagnosis was conformed by necropsy.

Two independent samples were obtained:

1. First Sample - Consisted of 26 patients ranging in age from 45 to 85 years with a mean age of 65 years. Ten were classified as AD and 16 as MID. This sample was drawn from all patients evaluated by the Neuropsychology Laboratory in 1974.

2. Second sample - Consisted of 31 patients ranging in age from 39 to 83 with a mean age of 63 years. Seventeen were classified as AD and 14 as MID. This sample was obtained from all the patients evaluated in 1975.

Clinical Diagnostic Classification Perez et al (1975a) have previously presented a detailed criteria for es- tablishing the diagnosis of MID and AD. The same criteria was followed in the present study. The diagnostic evaluation included the results of the medical and neurological examination as well as cisternography, regional cerebral blood flow studies, aorto-cranial angiograms, pneumoencephalograms, electroencephalograms as well as computerized axial tomography. The present WAIS results were not included in the evaluation. In all cases systemic disorders causing dementia were excluded such as neurosyphilis, vitamin B deficiency, folate deficiency, uremia and hypothyroidism.

The patients were classified into the following two groups of dementia:

Multi-infarct dementia (MID): The dementing process in these patients was associated with documented risk factors for cerebrovascular disease (Kannel et al, 1971), particularly a longstanding history of hypertension. The clinical course of the dementia was characterized by episodic strokes with cumulative worsening of mentation plus associated transient cerebral ishemic episodes in either the carotid or vertebrobasilar arterial territories or both (Hachinski et al, 1974).

Alzheimer's Disease (AD): These patients presented with a history of chronic progressive dementing process without risk factors or evidence of cerebrovascular disease. The clinical course in these patients was not characterized by episodic worsening of mentation as typically occurs in patients with cerebrovascular disease. There was no history of transient cerebral ischemic attacks, but a steadily progressive deterioration of intellectual functions.

Neuropsychological Test Procedures: A short form of the WAIS specifically modified for the examination of elderly patients was used (Perez et al, 1975a). This form comprised 6 of the 11 WAIS subtests. These included the following three verbal subtests: Information (INF), Arithmetic (ARITH) and Similarities (SIM). Three performance subtests were used; these included Picture 
Completion (Pic-Com). Block Design (Block-Des) and Picture Arrangement (Pic-Arr). A full scale IQ, Verbal IQ, Performance IQ, and raw scores for each of the individual subtests were obtained on every patient.

\section{RESULTS} The data was first analyzed by mean comparisons of each dependent variable between the two diagnostic groups for each independent sample.

First Sample: Inspection of Table 1 reveals that the two diagnostic groups differed significantly in levels of education with the AD group significantly better educated, and Performance IQ (PIQ) scores, with
Univariate Statistical Procedures:

the MID group performing significantly better. No other variable was found to be statistically different.

Second Sample: Table 2 presents the results for the second sample. No statistically significant differences were found for any variable studied between the groups. The education variable approached significance at the $p=0.5$ level.

Maximum $R$-Square Improvement Stepwise Regression: For conceptual and practical purposes it is important to detect possible patterns of intellectual performance for the two diagnostic groups on the multiple measurements obtained. In order to identify which combination of the 11 dependent variables produced the

TABLE I

\section{MEAN WAIS SCORES COMPARISON BETWEEN AD AND MID}

First Sample

\begin{tabular}{lrrrrr} 
& \multicolumn{2}{c}{ Multi-Infarct } & \multicolumn{2}{c}{ Alzheimer's } & \\
Variables & Mean & S.D.* & Mean & S.D.* & t-statistic \\
\hline 1 Age & 69.25 & 11.42 & 62.20 & 11.42 & 1.530 \\
2 Education & 10.25 & 4.02 & 13.70 & 3.53 & $2.2250^{* *}$ \\
3 Verbal IQ & 86.75 & 23.43 & 75.00 & 21.88 & 1.2752 \\
4 Performance IQ & 85.31 & 16.37 & 71.60 & 12.27 & $2.2732^{* *}$ \\
4 Full Scale IQ & 85.56 & 20.49 & 72.30 & 17.79 & 1.6853 \\
6 Information & 10.25 & 7.31 & 8.30 & 7.78 & 0.6462 \\
7 Arithmetic & 5.13 & 5.26 & 4.70 & 4.16 & 0.2159 \\
8 Similarities & 6.25 & 6.74 & 4.40 & 5.68 & 0.7213 \\
9 Picture Completion & 5.00 & 4.24 & 4.00 & 3.71 & 0.6123 \\
10 Block Design & 12.63 & 9.76 & 7.00 & 8.18 & 1.5166 \\
11 Picture Arrangement & 8.63 & 7.74 & 5.80 & 6.14 & 0.8026 \\
\hline
\end{tabular}

${ }^{*}$ S.D. $=$ Standard Deviation

$* * p<.05$, d.f. 24

TABLE II

MEAN WAIS SCORED COMPARISON BETWEEN AD AND MID

Second Sample

\begin{tabular}{lrrrrr} 
& \multicolumn{2}{c}{ Multi-Infarct } & \multicolumn{2}{c}{ Alzheimer's } & \\
Variables & Mean & S.D.* & Mean & S.D.* & t-statistic \\
\hline 1 Age & 63.85 & 10.58 & 63.35 & 10.51 & 0.1270 \\
2 Education & 10.23 & 4.42 & 12.82 & 3.00 & 1.9133 \\
3 Verbal IQ & 85.77 & 18.25 & 86.94 & 17.29 & 0.1797 \\
4 Performance IQ & 81.85 & 16.80 & 78.76 & 18.93 & 0.4634 \\
5 Full Scale IQ & 83.38 & 16.13 & 82.41 & 18.28 & 0.1518 \\
6 Information & 9.92 & 5.60 & 11.75 & 5.19 & 0.9092 \\
7 Arithmetic & 6.38 & 3.38 & 6.05 & 3.53 & 0.2553 \\
8 Similarities & 6.08 & 6.22 & 6.05 & 5.47 & 0.0112 \\
9 Picture Completion & 5.92 & 3.37 & 6.29 & 4.83 & 0.2330 \\
10 Block Design & 14.15 & 11.53 & 11.41 & 11.11 & 0.6591 \\
11 Picture Arrangement & 8.61 & 6.60 & 8.00 & 5.83 & 0.2706 \\
\hline
\end{tabular}

*S.D. = Standard Deviation "best" statistical model that discriminated between the two diagnostic groups a maximum $R$-square $\left(\mathbf{R}^{2}\right)$ improvement stepwise regression was performed. This procedure finds first the one-variable model producing the highest $\mathbf{R}^{2}$ statistics. $R^{2}$ is the square of the multiple correlation coefficient and is equal to the proportion of the dependent variable's total variance which is accounted for by the model. Then another variable, the one which would yield the greatest increase in $\mathrm{R}^{2}$, is added. The technique continues adding each dependent variable one by one to the model until all variables are included. Any two models can be compared for predictive accuracy by testing the difference between their $R^{2}$ 's with $F$ tests. The Statistical Analysis System (SAS) computer program for multivariate analysis developed at the University of North Carolina was used. For a more detailed explanation of the $\mathrm{R}^{2}$ technique see Perez et al, (1975b) and Kerlinger and Pedhuzar (1973).

First Sample: Table 3 presents the Maximum $\mathrm{R}^{\mathbf{2}}$ results for the first sample. The "best" statistical model found was the two variable model including education (EDU) and Full IQ, accounting for $40 \%$ of the variance. Addition of any other variable to the model did not increase $R^{2}$ significantly. The eleven variable model accounted for $48 \%$ of the variance. No significant difference was found between the two variable model and the 11 variable model.

Second Sample: Inspection of Table 4 reveals that the "best" statistical model found was the one variable model including EDU, accounting for $20 \%$ of the variance. No other variable added to the model increased $\mathbf{R}^{2}$ significantly. The eleven variable model accounted for $39 \%$ of the variance.

Discriminant Function Analysis A discriminant function analysis (Cooley and Lohnes, 1971) was performed on the 11 predictor variables and the two diagnostic groups. The multiple discriminant analysis produced a set of coefficients or weights for the various dependent measures 
TABLE III

WAIS MAXIMUM R-SQUARE IMPROVEMENT STEPWISE REGRESSION

For MID and AD - First Sample

\begin{tabular}{|c|c|c|c|c|}
\hline $\begin{array}{l}\text { Number } \\
\text { In Model }\end{array}$ & Variables in Model & $\mathrm{R}^{2}$ & $\begin{array}{c}\text { F-Value for } \\
\text { Increment }\end{array}$ & $\mathrm{p}<$ d.f. \\
\hline 1. & PIQ & 0.1772 & & \\
\hline 2. & EDU; FIQ & 0.3986 & 8.47 & $.01 \quad 1,23$ \\
\hline 3. & EDU; FIQ; PIC-COM & 0.4450 & 1.84 & N.S. 1,22 \\
\hline 4. & EDU; VIQ; FIQ; PIC-COM & 0.4533 & 0.32 & N.S. 1,21 \\
\hline 5. & EDU; VIQ; PIQ; FIQ; PIC-COM & 0.4607 & 0.28 & N.S. 1,20 \\
\hline 6. & EDU; VIQ; PIQ; FIQ; ARITH; PIC-COM & 0.4631 & 0.09 & N.S. 1,19 \\
\hline 7. & $\begin{array}{l}\text { EDU; VIQ; FIQ; INF; ARITH; PIC-COM; } \\
\text { PIC-ARR }\end{array}$ & 0.4686 & 0.36 & N.S. 1,17 \\
\hline 8. & $\begin{array}{l}\text { EDU; VIQ; FIQ; INF; ARITH; SIM; } \\
\text { PIC-COM; PIC-ARR }\end{array}$ & 0.4795 & 0.02 & N.S. 1,16 \\
\hline 9. & $\begin{array}{l}\text { AGE; EDU; VIQ; FIQ; INF; ARITH; SIM; } \\
\text { PIC-COM; PIC-ARR }\end{array}$ & 0.4803 & 0.01 & N.S. 1.15 \\
\hline 10. & $\begin{array}{l}\text { AGE; EDU; VIQ; FIQ; INF; ARITH; SIM; } \\
\text { PIC-COM; BLOCK-DES; PIC-ARR }\end{array}$ & 0.4807 & 0.01 & N.S. 1.14 \\
\hline 11. & $\begin{array}{l}\text { AGE; EDU; VIQ; FIA; INF; ARITH: } \\
\text { SIM; PIC-COM; BLOCK-DES; PIC-ARR }\end{array}$ & 0.4811 & & \\
\hline
\end{tabular}

TABLE IV

WAIS MAXIMUM R-SQUARE IMPROVEMENT STEPWISE REGRESSION For MID and AD - Second Sample

\begin{tabular}{|c|c|c|c|c|}
\hline $\begin{array}{l}\text { Number } \\
\text { In Model }\end{array}$ & Variables in Model & $\mathbf{R}^{2}$ & $\begin{array}{l}\text { F-Value for } \\
\text { Increment }\end{array}$ & $\mathrm{p}<\mathrm{d} . \mathrm{f}$. \\
\hline 1. & EDU & 0.1957 & & \\
\hline 2. & EDU-PIQ & 0.2888 & & N.S. 1,20 \\
\hline 3. & FDU $\cdot$ FIO INF & & 1.077 & N.S. 1,25 \\
\hline 3. & EDU; FIQ; INF & 0.3193 & 0.6585 & N.S. 1,24 \\
\hline 4. & EDU; FIQ; ARITH; PIC-COM & 0.3382 & 0407 & $N S \cdot 122$ \\
\hline 5. & AGE; EDU; FIQ; INF; PIC-COM & 0.3508 & 0.427 & N.S. 1,23 \\
\hline 6. & AGE; EDU; FIQ; INF; ARITH; PIC-COM & 0.3624 & 0.3828 & N.S. 1,22 \\
\hline 7. & AGE; EDU; FIQ; INF; ARITH; SIM; PIC-COM & 0.3685 & 0.1936 & N.S. 1,21 \\
\hline 8. & $\begin{array}{l}\text { AGE; EDU; PIQ; FIQ; INF; ARITH; SIM; } \\
\text { PIC-COM }\end{array}$ & 0.3758 & 0.1486 & $\begin{array}{l}\text { N.S. } 1,20 \\
\text { N.S. } 1,19\end{array}$ \\
\hline 9. & $\begin{array}{l}\text { AGE; EDU; VIQ; PIQ; FIQ; INF; ARITH; } \\
\text { SIM; PIC-COM }\end{array}$ & 0.3809 & 0.074 & N.S. 1,18 \\
\hline 10. & $\begin{array}{l}\text { AGE; EDU; VIQ; PIQ; FIQ; INF; ARITH; } \\
\text { SIM; PIC-COM; PIC-ARR }\end{array}$ & 0.3836 & 0.049 & N.S. 1,17 \\
\hline 11. & $\begin{array}{l}\text { AGE; EDU; VIQ; PIQ; FIQ; INF; ARITH; } \\
\text { SIM; PIC-COM; BLOCK-DES; PIC-ARR }\end{array}$ & 0.3855 & & \\
\hline
\end{tabular}


which best separate or discriminate the two different diagnostic categories. The between group variance is maximized relative to the within group variance. A composite discriminant predictor score was then computed for each patient based on his or her raw scores and the optimal lambda weightings $(\lambda)$ for each variable. Based on this composite score, each patient was then classified into one of the two diagnostic categories. A Chi-Square $\left(x^{2}\right)$ test was then performed in order to measure the distributions of the two diagnostic groups.

First Sample: Table 5 shows the discriminant function classification for the first sample. Eighty-one percent of the patients were correctly classified by the 11 predictor variables. The $\mathrm{x}^{2}$ was not significant thus the pooled covariance matrix was used in the discriminant function analysis. The two groups tended to overlap in their probability distribution.

Second Sample: Inspection of Table 6 reveals a valid positive hit rate of $100 \%$. The discriminant function analysis classified all patients correctly. The $\mathrm{x}^{2}$ was statistically significant thus the within covariance matrices were used in performing the discriminant function analysis. The two groups were found to be discrete.

TABLE V

Wais Discriminant Function Classification

For MID and AD - First Sample

\begin{tabular}{ccc} 
From Group & MID & AD \\
\hline MID & $14(87 \%)$ & $2(13 \%)$ \\
AD & $3(30 \%)$ & $7(70 \%)$ \\
\hline
\end{tabular}

Valid positive hit rate $-81 \%$

$x^{2}=85.54$ with 66 d.f. $p \geqq .05$ (N.S.)

TABLE VI

Wais Discriminant Function Classification For MID and AD - Second Sample

\begin{tabular}{ccc} 
From Group & MID & AD \\
\hline MID & $13(100 \%)$ & 0 \\
AD & 0 & $15(100 \%)$ \\
\hline
\end{tabular}

Valid positive hit rate $-100 \%$

$x^{2}=93.226$ with 66 d.f. $p<.05$

\section{DISCUSSION}

The present study investigated the intellectual performance of carefully diagnosed patients with Alzheimer's disease and multi-infarct dementia. Two independent samples of patients were collected in order to ob- tain a measure of reliability and generality of the findings (Sidman, 1960).

The data was first analyzed by univariate statistical procedures. The results of the first sample indicate that even though the AD group

\section{SCALED SCORES}

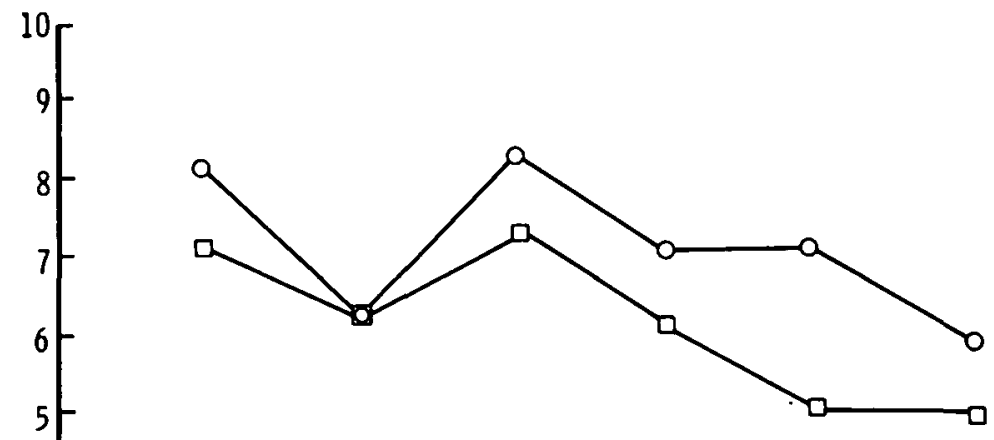

Figure l - Age corrected

Scaled scores for WAIS

Subtests - First Sample

$\bigcirc$ MID

$\square A D$

1

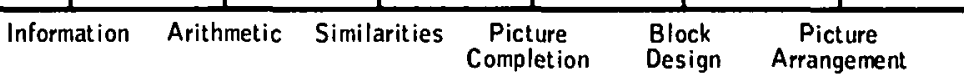

WAIS SUBTESTS

\section{SCALED SCORES}

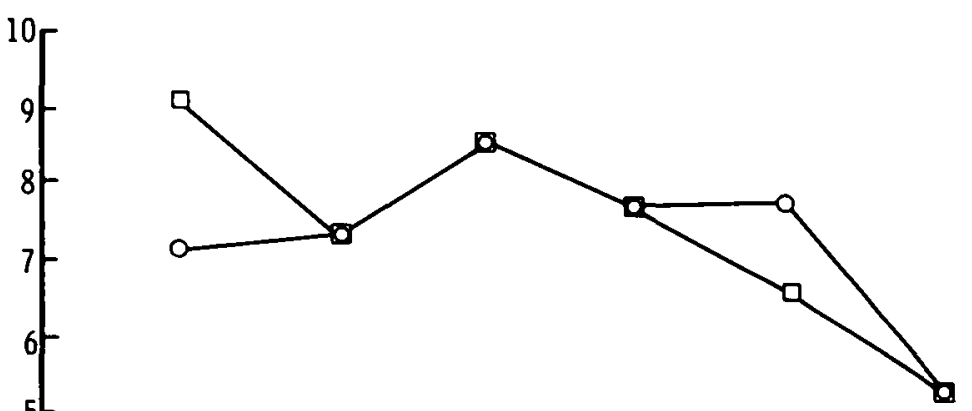

Figure 2 - Age corrected

Scaled scores for WAIS

Subtests - Second Sample

$\bigcirc$ MID

$\square$ Q $A D$

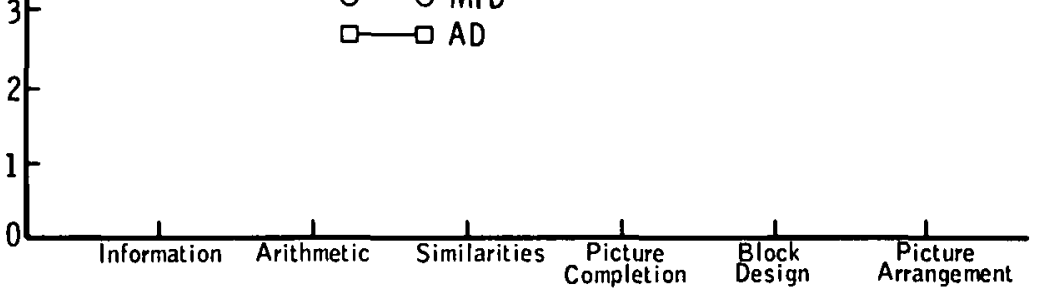

WAIS SUBTESTS 
performed consistently lower on each WAIS measure, there were only statistically significant differences in education level and Performance IQ (PIQ). It is important to note that the $A D$ group was better educated but performed less well overall. The second sample showed no statistically significant difference between the two groups. However, the education level approached significance with the AD group again having a higher education level. Figures 1 and 2 show visually the age corrected scaled scores of the various WAIS subtests for the two groups. A scaled score of 10 indicates average performance. Inspection of the figures indicate that both groups performed consistently lower than the average.

A closer inspection of the data indicates that the two independent MID samples were similar but there were obvious quantitative differences between the two A.D. groups. The second A.D. group performed consistently better. This sample's performance appears to be similar to the two MID groups. In order to analyze this quantitative difference between the two A.D. samples we carefully inspected the clinical records of each A.D. patient. We found that the average reported time since the first symptoms were noted and the neuropsychological evaluation for the first sample was $\mathbf{4 . 2}$ years and for the second sample was 3.2 years. This difference of one year progression of the disease between the two samples might account for the quantitative difference in the WAIS scores since A.D. is associated with progressive behavioral deterioration. Future behavioral studies should carefully control this relevant variable. Serial behavioral measures on A.D. patients are necessary in evaluating the nature as well as natural course of the psychological disturbances associated with A.D.

The findings of the first sample are consistent with previous results reported by this laboratory (Perez et al., 1975a). As before, the group with A.D. performed consistently lower on all WAIS measures. However, in the previous study the data was analyzed by means of an analysis of covariance with age and education as covariates which maximizes the differences between the groups.

The results of the discriminant function analyses performed on the 11 predictor variables and the two diagnostic groups are encouraging (see Tables 5 and 6). The hit rate for the first sample was $81 \%$ and $100 \%$ diagnostic accuracy was obtained for the second sample. These results are better than those previously reported (Perez et al., 1975) in which a $74 \%$ diagnostic accuracy was obtained. Statistically, the two diagnostic groups can be discriminated with a high level of accuracy using the WAIS subtests plus age and education as the predictor variables.

In order to detect possible patterns of intellectual performance for the two diagnostic groups as well as for heuristic and conceptual purposes a preliminary maximum $\mathbf{R}^{2}$ improvement stepwise regression was performed. This powerful multivariate analysis of regression technique supplements concepts of statistical significance with additional information concerning the relative efficiency of a particular model (i.e., proportion of variance accounted for by model) in discriminating the groups. The task is to trim away useless predictor information (i.e., insignificant sources of variance) and arrive at the simplest representation of the data without reducing the discriminatory accuracy. According to Ward and Jennings (1973), if a simple model and a less simple one can estimate sample means equally well, the estimates of the simpler model will, on the average, be closer to the parameter means than those produced by the less simple one. The first step was to identify the "best" (i.e., simplest) statistical model discriminating between the two groups (see Tables 3 and 4). The "best" model for the first sample was the two variable model including education level (EDU) and Full Scale IQ which accounted for $40 \%$ of the variance. For the second sample, the simplest model was the one variable model including education level.
Consistently the EDU variable was included in the simplest model discriminating the two groups in the two samples. The Alzheimer's groups had on the average three years more formal education. Careful inspection of the clinical records of each patient included in the two studies revealed that the chief complaint at the time of admission for every A.D. patient was memory or psychological problems. The typical MID patient presented with a primary physical disorder (i.e., hemiparesis or history of strokes) and psychological concerns were secondary. This difference in presenting symptoms might lead to sampling biases in the behavioral study of dementia. Educational and socioeconomic factors might select the patient with A.D. who is admitted for medical services. The MID patient will tend to seek medical treatment for his physical condition. However, the A.D. patient might tend to seek help for his memory and psychological problems primarily because of a higher previous level of functioning which makes subtle changes detectable by himself or members of the family. It is possible that in lower educational and socio-economic levels the psychological changes associated with A.D. go unnoticed longer and/or these cases tend to be admitted to state psychiatric institutions with the unfortunate diagnosis of "organic brain syndrome." These considerations indicate the importance of collecting a detailed social, psychological and medical history in patients with dementia. Demographic and epidemiological studies are urgently needed in the light of the present hypotheses.

The growing percentage of old people in society gives rise to a variety of health and social problems. Organic dementia is a major disorder afflicting the elderly. According to Juel-Nielsen (1975) about $10 \%$ of old people are demented, half of them severely, and in the over-80's this proportion rises to more than one in five. The financial burden in caring for such patients amounts to many billions of dollars per year. Despite their high incidence, dementing diseases have been 
of minimal interest to the clinician. This lack of interest stems mainly from two widely held misconceptions that dementia is part of the normal aging process, and that all dementing diseases are not treatable (Heilman and Wilder, 1971). These misconceptions have created a "psychogeriatric crisis" hampering adequate research and delivery of health services for the elderly. The present replication study provides additional support for the potential clinical and practical application of neuropsychological and behavioral procedures in identifying the psychological changes associated with the various diseases producing dementia (Perez et al., 1975a, b, c).

\section{REFERENCES}

COOLEY, W. W. and LOHNES, P. R. (1971). Multivariate data analysis. New York: John Wiley and Sons, Inc.

HACHINSKI, V. C., LASSEN, N. A. and MARSHALL, J. (1974). Multi-infarct dementia - a cause of mental deterioration in the elderly. Lancet, 2, 207-209.
HEILMAN, K. M. and WILDER, B. V. (1971). Evaluation and treatment of chronic simple dementias. Modern Treatment, 8, 219-230.

JUEL-NIELSEN, N. (1975). Epidemiology. In Modern Perspectives in the Psychiatry of Old Age. New York: Brunner/Matzel.

KANNELL, W. B., BLAISDELL, F. W., GIFFORD, R., HASS, W., MCDOWELL, F., MEYER, J. S., MILLIKAN, C. H., RENTZ, L. E. and SELTZER, R. (1971). Risk Factors in Stroke due to cerebral infarction. Stroke, 2, 423-428.

KARP, H. (1974). Dementias in adults. In Clinical Neurology, 3rd Edn., Vol. w. Edited by A. B. Baker and L. H. Baker. Harper and Row; Hagerstown, Md.

KERLINGER, F. N. and PEDHUZAR, E. H. (1974). Multiple regression in behavioral research. New York: Holt-Rinehart and Winston.

KRAL, V. A. (1972). Senile dementia and normal aging. Canadian Psychiatric Association Journal, 17, 25-30.

MEYER, J. S., WELCH, K. M. A., PEREZ, F. I., MATHEW, N. T., RIVERA, V. M., GEDYE, J. L., HRASTNIK, F., MIYAKAWA, Y., ADAIR, V., ACHARI, A. N., DODSON, R. F. Neurotransmitter failure in cerebral infarction, dementia and the aging brain. Paper presented at the symposium on "The Neurobiology of Aging" New York University Medical Center, (June 5-6, 1975).

PEARCE, J. M. S. and MILLER, F. (1973). Clinical aspects of dementia. London: Balliere Tindall.

PEREZ, F. I., RIVERA, V. M., MEYER, J. S., GAY, J. R.A., TAYLOR, R. L. and MATHEW, N. T. (1975 a). Analysis of intellectual and cognitive performance in patients with multi-infarct dementia, vertebrobasilar insufficiency with dementia and Alzheimer's disease. Journal of Neurology, Neurosurgery and Psychiatry, 38, 533-540.

PEREZ, F. I., GAY, J. R. A., TAYLOR, R. L. and RIVERA, V. M. (1975 b). Patterns of Memory Performance in the neurologically impaired aged. The Canadian Journal of Neurological Sciences, 1, 347-355.

PEREZ, F. I., GAY, J. R. A. and TAYLOR, R. L. $(1975$ c). WAIS Performance of Neurologically impaired aged. Psychological Reports, 37, 1043-1047.

POSER, C. H. M. (1975). The presenile dementias. (1975). Journal of the American Medical Association, 233, 81-84.

SIDMAN, M. (1960). Tactics of Scientific Research, New York: Basic Books.

WARD, J. and JENNINGS, E. (1973). Introduction to Linear Models. Englewood Cliff, New Jersey: Prentice Hall. 